Original scientific paper

\title{
SYNCHRONISATION OF CONTACTLESS VIBRATION MONITORING METHODS
}

\author{
Kovacic, B.; Mursec, L. \& Lubej, S. \\ University of Maribor, Faculty of Civil Engineering, Transportation Engineering and Architecture, \\ Smetanova 17, 2000 Maribor, Slovenia \\ E-Mail: bostjan.kovacic13@gmail.com,lmursec@gmail.com,samo.lubej@um.si
}

\begin{abstract}
Today, the analysis of the behaviour of structures represents an important area of engineering, where we are mainly interested in the response of the structure to certain influences.

The article and research are based on the theoretical foundations of structural monitoring using contactless methods and discuss the practical analysis and simulation of synchronization of structural response to various artificially induced load cases. The responses of the structure were recorded through various parameters, such as displacement, speed and acceleration, with the help of geodetic (Robotic Total Station - RTS and Global Navigation Satellite System - GNSS) and physical equipment (triaxial geophone). When using geodetic equipment, in addition to the possibility of final synchronization of results, we were also interested in the actual influence of the frequency of data acquisition on the accuracy of measured values. Special attention was paid to spectral analysis, to which we added practical value through data processing using Fourier transform algorithms.

(Received in November 2021, accepted in January 2022. This paper was with the authors 2 weeks for 2 revisions.)
\end{abstract}

Key Words: Model Synchronisation, Displacement Simulation, Geodetic Measurements, Physical Measurements

\section{INTRODUCTION}

In engineering practice, we often encounter the problem of determining the geometric properties of structures and their changes, which in a narrow sense defines the tasks of determining changes in the position and shape of the structure in relation to the environment depending on time. Deformations of structures generally occur due to external and internal influences on the structure, which are considered weather, tectonic and seismic influences, as well as other external influences resulting from static and dynamic loads on the structure.

Simultaneous monitoring of construction has gained in importance with the rapid development of structure. Due to the progress reflected in many new technologies, complexity and height of structures, control and consequent knowledge of the response of the structure to various influences is essential for their use and ultimately the existence [1,2]. About traits and behaviour we get in a timely manner. Control measurements are an important part of a wide field of monitoring. At their core, they also result in the timely detection and elimination of defects in the facility in question, which can ensure proper rehabilitation and further safe use. Several different measurement procedures and methods can be used to perform control measurements, but it is important to compare or synchronize the results with each other [3-15]. Most control measurements are performed in the form of load tests, which are a mandatory part of the analysis of structures both after the construction of a new facility and before increasing the load-bearing capacity of facilities with a span exceeding $10 \mathrm{~m}$. Types of test loads, scope, procedures and assessment of test results are determined by applicable standards and technical national regulations, and their implementation must comply with Eurocode standards for structures and bridges, SIST EN and applicable national regulations for concrete and steel structures. Their implementation thus directly provides information on the behaviour of the newly built facility, and their implementation on existing facilities can also significantly contribute to determining the actual condition of the structure for the needs of possible 
rehabilitation [16]. Simultaneously with the analysis of the response, the monitoring results also serve to verify and confirm the theoretical or design assumptions that were made before the construction of the facility. When observing the bridging structure, the vertical displacements and related deformations are primarily checked, as the latter have the greatest impact on the stability of the structure. Stress tests, in which knowledge of the input parameters of monitoring is very important, can basically be included in the control measurements of facilities. The exact definition of the number and weight of the load used in the test, the condition of the structure before and after the test, the specifications of the controlled elements and the measuring equipment used are important.

If you would like to obtain more detailed results of the observed object, it is recommended to use several independent methods of measuring the response of the structure. The results of the contactless vibration measurement methods used should be compared with each other, as presented in [15, 17]. Recently, many authors [18-25] have dealt with the use and accuracy of GNSS-derived results and ground-based scanners and ground-based radar interferometry [26] in determining the dynamic response and in various types of object monitoring.

\section{IMPLEMENTATION OF MONITORING}

To perform the monitoring, we used available non-invasive measuring equipment, geodetic robotic station Leica TS50 with additional program GeoCOM / ZG (the GeoCom / Zg program was developed at the University of Zagreb (Croatia), Faculty of Geodesy, and allows us larger sampling, up to 30 measurements per second), which allows us to increase sampling rate and TS30 with classic data acquisition, GNSS Topcon Hyper Pro and seismograph Instantel Minimate Plus. The characteristics of the equipment are given in Table I.

Table I: Characteristics of measuring equipment.

\begin{tabular}{|c|c|c|}
\hline \multicolumn{3}{|c|}{ Geodetic measurement equipment } \\
\hline Sensor & Measuring equipment & Frequency of signal acquisition $[\mathrm{Hz}]$ \\
\hline RTS50 & RTS Leica TS50 + GeoCOM / ZG & $26-30$ \\
\hline RTS30 & RTS Leica TS30 & $6-10$ \\
\hline GNSS & GNSS Topcon Hyper Pro & 10 \\
\hline \multicolumn{3}{|c|}{ Physical measuring equipment } \\
\hline Sensor & Measuring equipment & Frequency of signal acquisition $[\mathrm{Hz}]$ \\
\hline ACC1 & Instantel Minimate Plus & 250 \\
\hline
\end{tabular}

The selected and subsequently analysed facility is the Studenci footbridge, which is the smallest bridge on the Drava River in Maribor and is intended exclusively for pedestrians and cyclists. The main structure of the Studenci footbridge can be defined as a steel space bar, which was prefabricated in the workshop and finally assembled in segments $(L<12 \mathrm{~m})$ at the construction site. The spatial bar structure consists of three primary longitudinal tubes (one tube for the upper band and two for the lower band, connected by intermediate bars and diagonals. The maximum span of each section in the axis of the structure is $42 \mathrm{~m}$, representing the total length of the three spans. The choice of three spans is conditioned by the preservation of the supports of the original structure, transverse and torsional stiffness and stability. The axial distance of the upper and lower belt is $1.75 \mathrm{~m}$, which is reflected in the total design height of $2.05 \mathrm{~m}$. The axial distance of the lower tubes is $1.50 \mathrm{~m}$. The main structure with vertical curvature $R=4000 \mathrm{~m}$ is made entirely of structural steel of strength S355 [27].

The secondary structure is fully screwed to the main structure and consists of welded transverse cantilever and longitudinal rolled I beams. Transverse brackets, which end as fence posts, are attached to specially prepared attachments on the load-bearing structure. The beams 
in the longitudinal directions are connected to the IPE140 and IPE160 steel profiles. The roof or top structure is made entirely of wood. The footbridge is based or rests on previously implemented supports, which have been renovated and adapted to the new construction. From the point of view of implementation, the latter means that the intermediate pillars have been lowered and the end supports have been widened. The foundation of each support and the foundation rock are additionally reinforced and connected by jet-grouting piles $15 \mathrm{~m}$ long $(8 \mathrm{~m}$ in the support and $7 \mathrm{~m}$ in the base), whose diameter in the gravel rock reached $70 \mathrm{~cm}$ [27].

\section{MONITORING RESULTS}

For monitoring purposes, we performed several weighting cases from walking towards and away from the measuring point, running towards and away from the measuring point to jumps on the object. In the results, we will give only the values of the case of running away from the measuring point, because with this weighting case we most excited the oscillations of the structure.

\subsection{Results obtained by geodetic methods}

A stressful example in the monitoring was a run across the entire footbridge away from the measuring point, which was performed by two people who passed the centric bridge in a time interval of about 40 seconds. Due to the assumed slightly larger vertical displacements, the analysis at the beginning of the selected interval also included a small part of the own oscillation of the footbridge, which then provided a good starting point for subsequent analysis and synchronization. Based on the following figures summarized in Fig. 1, it can be concluded that the displacement course in the case of measurement with robotic total station RTS Leica TS50 with $26 \mathrm{~Hz}$ sampling and RTS Leica TS30 with $6 \mathrm{~Hz}$ sampling is very similar, but minor differences reappear in the accuracy of the measured results, which can certainly be attributed to the frequency of sampling.

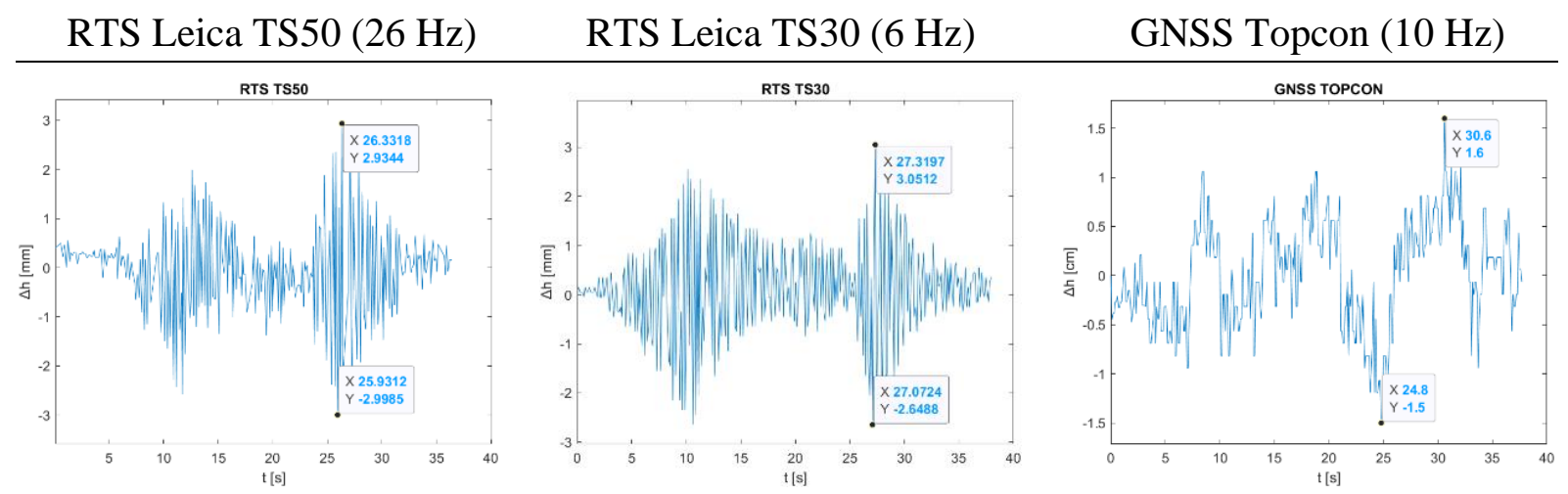

Figure 1: Results - running across the footbridge (geodetic methods).

Data acquisition with a GNSS receiver can be defined as partially adequate compared to the others in the case of running, where there are slightly faster responses than in the case of selfoscillation. Even if we subtracted the natural oscillation from the measured absolute vertical displacements, we would get relatively comparable, but still excessive results compared to the measurements of robotic total stations. In the case of running, the so-called oscillation phase is also clearly visible, where two intense oscillation intervals occur during the observation. The occurrence of intervals coincides with running through the supports of the footbridge. It is also evident that running over a more distant support has a slightly greater impact and causes greater displacements in the vertical direction. We can also notice a big difference or the relationship between the natural oscillation and the oscillation caused by running over the footbridge. The 
measured maximum vertical displacements and their absolute magnitudes are summarized in Table II below.

Table II: Results - running over the footbridge (geodetic methods).

\begin{tabular}{|c|c|c|c|c|}
\hline \multirow{2}{*}{ Instruments } & \multirow{2}{*}{ Frequency } & \multicolumn{3}{|c|}{ Vertical displacements [mm] } \\
\cline { 3 - 5 } & & Min. & Max. & $\boldsymbol{\Delta}$ \\
\hline RTS Leica TS50 & $26 \mathrm{~Hz}$ & -2.9985 & 2.9344 & 5.9329 \\
\hline RTS Leica TS30 & $6 \mathrm{~Hz}$ & -2.6488 & 3.0512 & 5.7000 \\
\hline GNSS Topcon & $10 \mathrm{~Hz}$ & -19.00 & 8.00 & 27.00 \\
\hline
\end{tabular}

\subsection{Results obtained by physical methods}

The work with physical methods differed relatively considerably from the described geodetic methods in terms of the method of data collection. In the following, only the initially measured or basic results of the performed measurements, which were obtained using the Instantel Minimate Plus seismograph, are shown. The results in the case of using the Instantel Minimate Plus seismograph are exported directly from the computer program Instantel Blasware, which at this point was used only to view and print the measured signals. The protocol used to display and print the results in our case was DIN4150.

The measured results in the case of running over the footbridge away from the measuring point are collected in Table III. Fig. 2 shows a graphical representation of the response of the structure in the transverse (red), longitudinal (blue) and vertical (green) directions. From the visual comparison it is evident that the course of the measured quantities coincides or is relatively similar to the figure of the measured vertical displacements in the case of geodetic methods. Similar to the case of geodetic measurements, the phasing of the figures is clearly visible, which again coincides with the movement or flow through the supports.

Table III: Results - running across the footbridge (physical methods).

\begin{tabular}{|l|c|c|c|c|}
\hline \multicolumn{1}{|c|}{ Physical quantity } & Transverse & Vertical & Longitudinal & Unit \\
\hline$P P V($ Peak Particle Velocity) & 11.5 & 18.8 & 1.21 & $\mathrm{~mm} / \mathrm{s}$ \\
\hline Acceleration (Peak Acceleration) & 0.103 & 0.0812 & 0.0696 & $\mathrm{~g}$ \\
\hline Displacement (Peak Displacement) & 0.316 & 0.893 & 0.0373 & $\mathrm{~mm}$ \\
\hline Frequency (Frequency) & 7.2 & 7.4 & 7.4 & $\mathrm{~Hz}$ \\
\hline
\end{tabular}
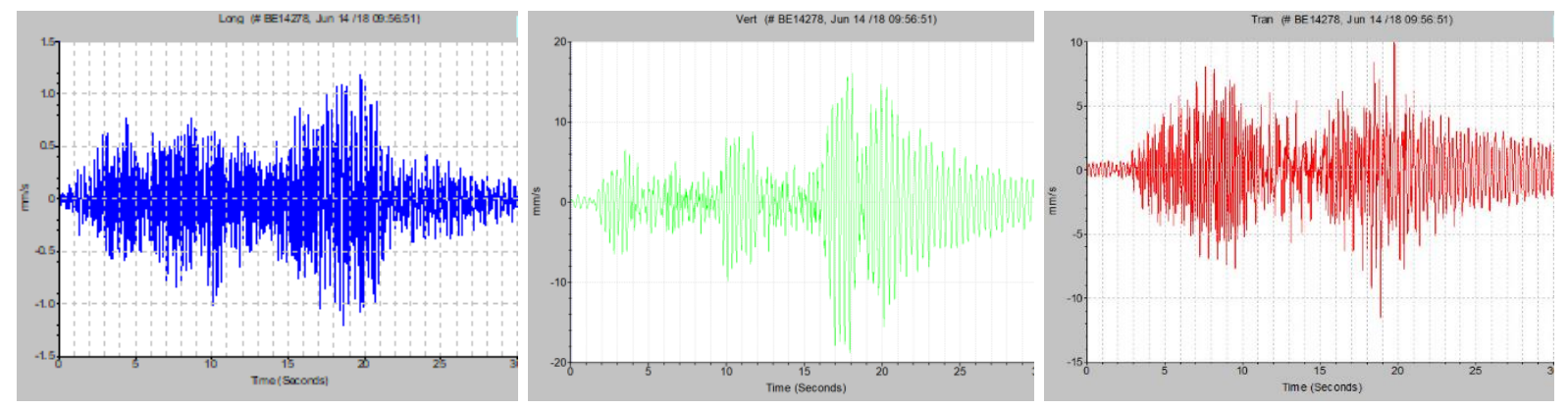

Figure 2: Results - running across the footbridge (physical methods).

The left graph shows the $P P V$ in the transverse direction, the centre the $P P V$ in the vertical direction and the left the $P P V$ in the longitudinal direction. 


\section{ANALYSIS OF RESULTS AND SYNCHRONIZATION}

Analysis and synchronization of results were performed specifically for geodetic and physical methods. Due to better mutual comparison and interpretation, due to the difficulty of direct synchronization after analysis and presentation of the results of spectral analysis performed for physical methods, we also summarized directly comparable quantities obtained in both geodetic and physical measurements. An important difference, which at the beginning indicated a potentially difficult synchronization of geodetic and physical methods, was the original mismatch of the measured quantities. An additional problem is the fact that in the case of geodetic methods we obtained absolute values, and in the case of physical methods relative values. By obtaining information on displacements in the case of geodetic methods and information on velocities and accelerations in the case of physical methods, the actual synchronization and mutual comparison of results was performed mainly on visual analysis of graphs and only certain values obtained by spectral analysis procedures. Although we obtained information for the remaining directions during the monitoring, we limited the processing to the analysis of the measured vertical displacements or velocities and accelerations. Namely, we found that the vertical quantities are larger than the quantities in the horizontal or longitudinal direction.

Signal processing and subsequent spectral analysis were performed exclusively with computer programs. For the purposes of the calculation, the MatLab computer program was used mainly when working with the results of geodetic methods. It was used for the classical analysis of the basic graphs of vertical displacements as a function of time $(v(t))$ and the directly related further spectral analysis of individual graphs of individual events. Spectral analysis was based on fast Fourier transformations or so-called FFT analysis. For the example of fast Fourier signal transformation, we mainly used a special mathematical algorithm called the Lomb or Lomb-Scargle periodogram [28]. With the algorithm, for the needs of mutual comparison of geodetic methods in the first phase, we performed the transformation of the original or basic graphs into Lomb-Scargle periodogram or Lomb-Scargle spectral approximation. It should be noted that the analyses of geodetic measurements were analysed with FFT procedures in the frequency range $0-1 \mathrm{~Hz}$. The reason for the latter was mainly assumed to be a better match of the results in the mentioned area. Furthermore, we also determined the corresponding frequency spectrum and its maximum values or amplitudes $A(f)$ from the basic signal. As part of the second analysis of geodetic measurement signals, we used the SignalLab Sigview program. In this case, we again primarily used previously prepared basic signal files, which were imported into the mentioned program in the form of text files. This time the analysis was entirely limited to the treatment of the entire source signals of the surveying equipment. Using the commands, we performed FFT analysis for each input signal, but this time we were interested in the general frequency spectrum and the maximum values of the entire source signal. Based on the results of FFT analysis and plotted graphical flows, we finally determined the corresponding dominant frequency and maximum amplitude for each input signal. We can summarize that the analysis of geodetic measurements were performed in the case of the general frequency spectrum and in the case of the corresponding Lomb-Scargle spectral approximations in the selected range.

The analysis of physical measurement data obtained with Instantel equipment was performed in a slightly different way or differed from the previously mentioned procedures. In the latter measurements, we used the official software of the manufacturer, namely the Instantel Blastware program. The specificity of performing measurements with the Instantel Minimate Plus seismograph is defined by the measurement protocol, which follows or limits the measured vibration values according to selected national standards. The measured signals are thus automatically stored on the measuring device in their original form or file format. Since the 
measuring equipment basically uses the Blastware program in its basic form, further analysis of the results with the computer version of the program is relatively simple.

\subsection{Run over the footbridge away from the measuring point}

Spectral analysis of the signals of running across the footbridge away from the measuring point showed that the measured results can be compared and synchronized practically well enough. In the first phase, the analysis was performed again from the point of view of the values of certain Lomb-Scargle periodograms in the range $0-1 \mathrm{~Hz}$ and frequency spectral of individual periodograms, where only maximum amplitudes could be determined. The phasing of the graphs, which first appeared in the graphical representations of the displacement results, was clearly evident also in the case of the obtained frequency spectrum. The corresponding spectral approximations of the measured signals in the form of a Lomb-Scargle periodogram for the $0-1 \mathrm{~Hz}$ range, shown in Fig. 3, were also relatively similar after the visual analysis of the graphical flows. The positions of the maximum values in the frequency spectrum of the periodogram, in general, again coincided with the places of running through the supports, and in the case of robotic total stations they also defined relatively comparable values of amplitudes. Deviations from the position and amplitude values are clearly evident in the case of GNSS treatment. The frequency spectral of the periodograms are shown in Fig. 4, and the calculated or determined values of the spectral analysis of this event are summarized in Table IV, where $A(f)$ is the frequency spectrum of the periodogram with maximum amplitudes, and the $x$-axis $f$ is informative and has no unit.

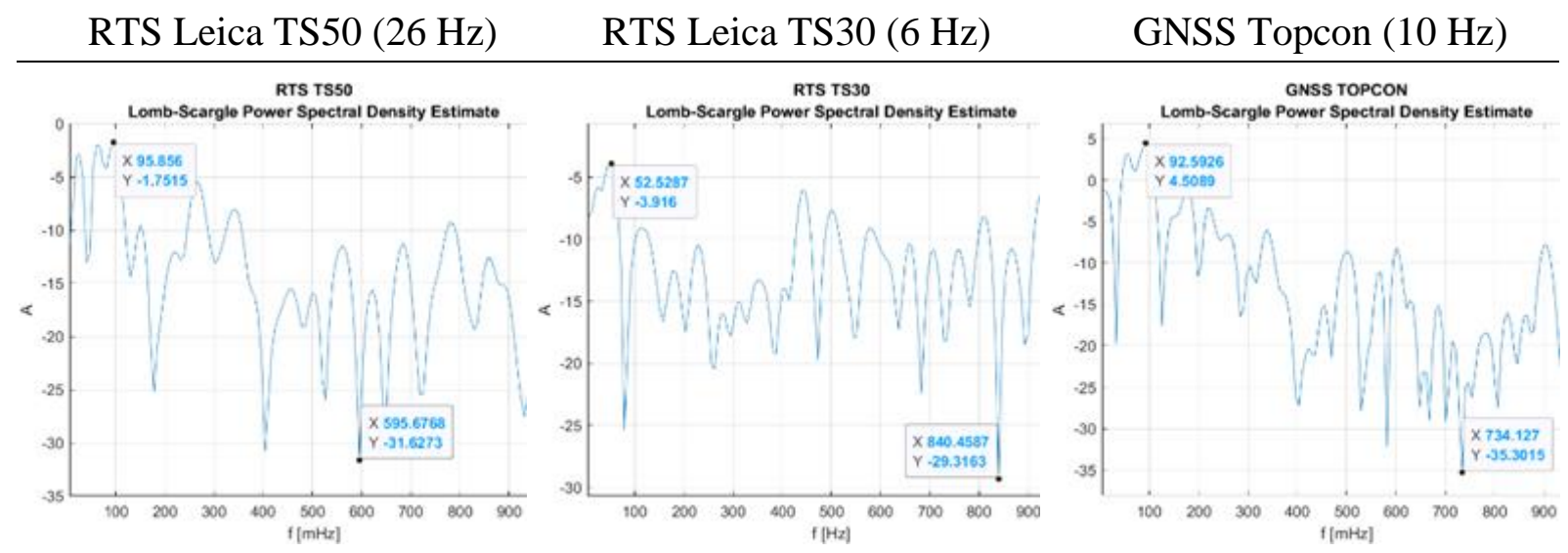

Figure 3: Analysis: running over the footbridge - periodogram $0-1 \mathrm{~Hz}$ (geodetic methods).

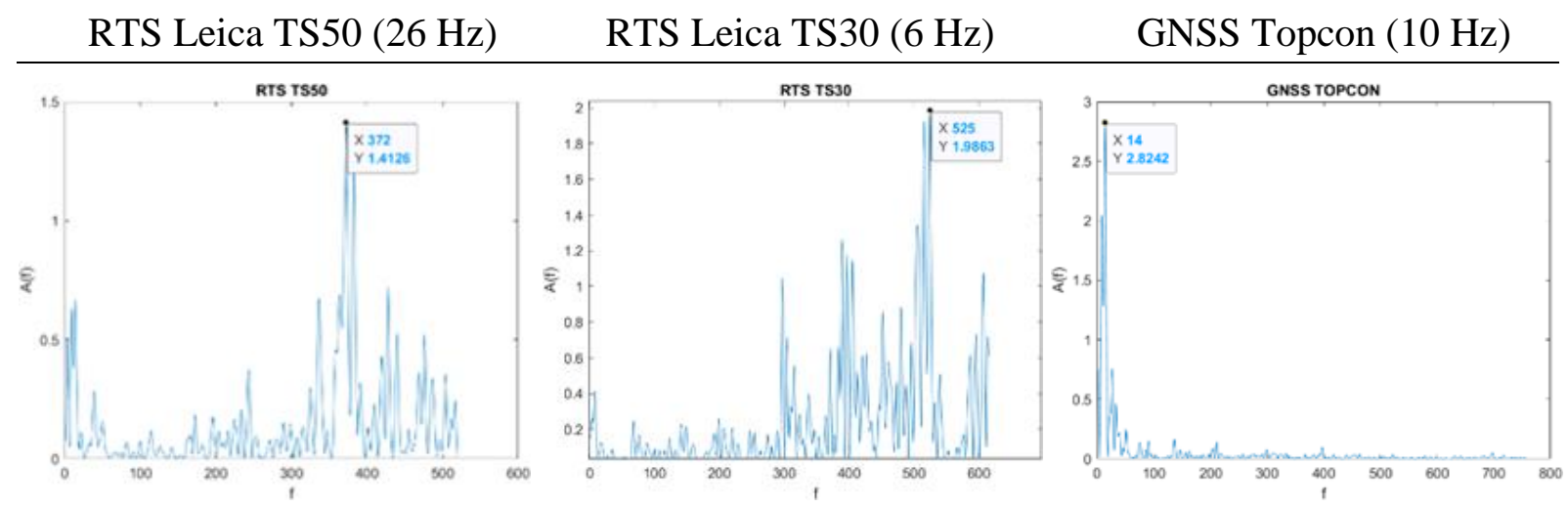

Figure 4: Analysis: running across the footbridge - frequency spectrum of the periodogram (geodetic). 
Table IV: Analysis: running across the footbridge - results of the periodogram (geodetic).

\begin{tabular}{|l|c|c|c|c|c|}
\hline \multirow{2}{*}{ Instruments } & \multirow{2}{*}{ Frequency } & \multicolumn{2}{|c|}{ Lomb-Scargle periodogram $(0-1 \mathrm{~Hz})$} & \multirow{2}{*}{$\boldsymbol{A}(\boldsymbol{f})$} \\
\cline { 3 - 5 } & & Min. & Max. & $\boldsymbol{\Delta}$ & \\
\hline RTS Leica TS50 & $26 \mathrm{~Hz}$ & -31.6273 & -1.7515 & 29.8758 & 1.4126 \\
\hline RTS Leica TS30 & $6 \mathrm{~Hz}$ & -29.3163 & -3.916 & 25.4003 & 1.9863 \\
\hline GNSS Topcon & $10 \mathrm{~Hz}$ & -35.3015 & 4.5089 & 39.8104 & 2.8242 \\
\hline
\end{tabular}

The results show that the deviations of the results of the analysis of periodograms in relation to the considered previous findings are relatively small overall. In comparison with all the events analysed so far, we further found that in the case of higher sampling frequency there was again a slightly larger difference between the maximum values of the periodogram in the range $0-1 \mathrm{~Hz}$, and certain amplitudes were lower than in signals obtained with lower frequency of data capture.

We attributed slightly greater representativeness to the latter, although we described the actual differences between the results of robotic total stations as negligibly small in practical implementations. The GNSS deviations were again quite large compared to the remaining values. We judged that the expected differences reappeared due to the measuring range or the declared accuracy of the measuring device, and that it would be sensible to process the initial analysed signal for a better match. Based on the second analysis of the initial signals, where we determined the frequency spectrum and the corresponding determined values of the dominant frequencies and amplitudes, we found that the obtained results are again in the expected mutual relations. In the third case, in the analysis of RTS measurements, despite the small deviation of the dominant frequencies, the amplitude values were quite comparable. When considering the position, we can observe that the place of occurrence of the maximum amplitude with respect to the expressed spectrum coincides well this time in the case of RTS. Large deviations from the point of view of frequency and amplitude occurred in the GNSS frequency spectrum. The values were slightly more comparable or meaningful compared to the second event, as this time we also expected larger amplitudes due to a slightly higher dynamic load. The obtained results were also incomparable in terms of the results from the first analysis of the signal periodogram, although it should be noted that the positions of maximum amplitude coincided well. Table $\mathrm{V}$ summarizes the results of geodetic measurements.

Table V: Analysis: running across the footbridge - results (geodetic).

\begin{tabular}{|l|c|c|c|}
\hline \multicolumn{1}{|c|}{ Instruments } & Capture & Dominant frequency & Amplitude \\
\hline RTS Leica TS50 & $26 \mathrm{~Hz}$ & 2.5555 & 0.5200 \\
\hline RTS Leica TS30 & $6 \mathrm{~Hz}$ & 3.3116 & 0.4046 \\
\hline GNSS Topcon & $10 \mathrm{~Hz}$ & 0.0781 & 4.8623 \\
\hline
\end{tabular}

We can conclude that even in the case of the analysed event, we confirmed the possibility of mutual comparison and synchronization of the measured signals obtained with RTS. We have only partially confirmed this possibility for the results obtained with the GNSS receiver.

\subsection{The synchronization}

In the illustrations that follow, we have added an informative course of GNSS measurements to the graph of individual measurements synchronized with RTS only for a broader interpretation of the results. The latter shows that, despite its shortcomings, it basically follows the actual response of the structure or is relatively similar to the course of response measured by RTS stations. 
Fig. 5 thus represents the response of the run away from the measuring point. We can summarize that the graphical presentation clearly shows the coincidence of the measured results with the corresponding or expected minor deviations. The already mentioned phase of the response is also clearly visible, and the places or times of the achieved maximum knowledge also coincide clearly. The information flow of vertical movements with the GNSS device (green) is shown on a reduced scale solely for the purpose of easier comparison of all results.

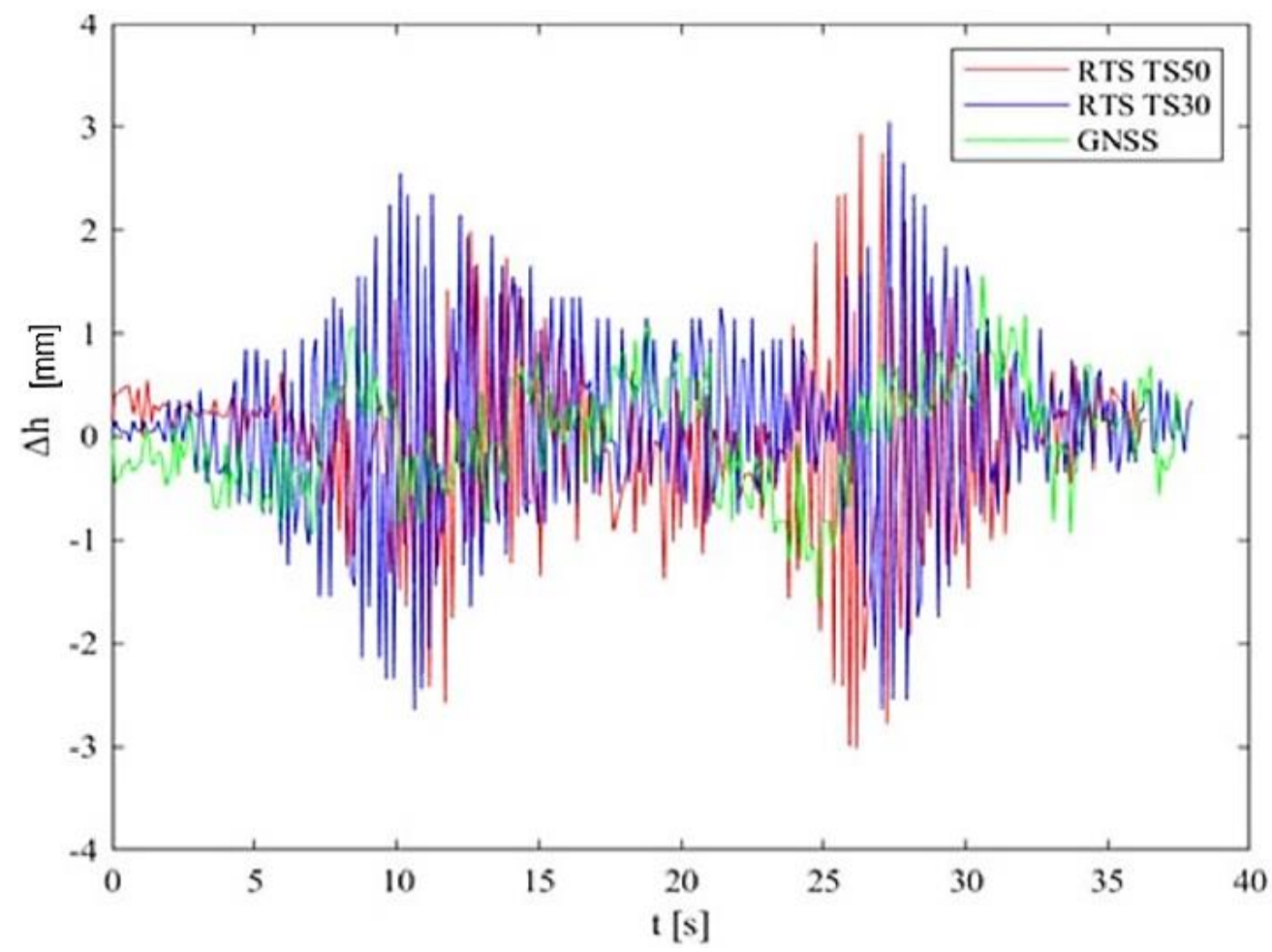

Figure 5: Synchronization of movements - running across the footbridge (geodetic).

\section{DISCUSSION}

In the final phase of the analysis of geodetic methods, we can therefore re-summarize that, taking into account the relevant theoretical starting points and appropriate mathematical processing and data analysis, geodetic methods can generally be described as mutually comparable. Regarding the influence of the capture frequency on the accuracy of the obtained results, we found that the latter has basically only a small influence on the obtained results in the case of the monitoring of the Studenci footbridge. The perceived small deviations between the measurements of robotic stations were also partly attributed to potential differences in the implementation of monitoring - especially the actual triggering of measurements and external influences on measuring equipment. The obtained values of GNSS measurements were also marked as appropriate and partly comparable from the point of view of the obtained relations between RTS measurements. Another important finding was that the declared accuracy or working range of the measuring device is much more important for representative data. It should be noted that the measured results obtained with RTS exceeded the accuracy of the GNSS measuring device. Based on the presented findings, we concluded that direct mutual synchronization is generally possible only for RTS results in part or indirectly, but also for monitoring results obtained with GNSS measuring equipment. Table VI summarizes all the results of monitoring the footbridge, which were the subject of mutual comparison of geodetic and physical measurements. 
Table VI: Summary of the results of spectral analysis (geodetic and physical methods).

\begin{tabular}{|l|c|c|c|}
\cline { 2 - 4 } \multicolumn{1}{c|}{} & \multicolumn{2}{c|}{ Geodetic Equipment } & Physical Equipment \\
\hline \multicolumn{1}{c|}{ Moments } & $\begin{array}{c}\text { RTS Leica } \\
\text { TS50 }(26 \mathrm{~Hz})\end{array}$ & $\begin{array}{c}\text { RTS Leica } \\
\text { TS30 }(6 \mathrm{~Hz})\end{array}$ & $\begin{array}{c}\text { Instantel Minimate } \\
\text { Plus (250 Hz) }\end{array}$ \\
\hline Run over the footbridge away from the measuring point \\
\hline Displacement & 5.9329 & 5.7000 & 0.893 \\
\hline Dominant frequency & 2.5555 & 3.3116 & 2.781 \\
\hline Amplitude & 0.5200 & 0.4046 & 2.222 \\
\hline
\end{tabular}

Monitoring the behaviour of various structures is extremely important today from an engineering point of view. The field of analysis of building structures deals with this, on the basis of which we get a detailed insight into the behaviour of buildings that are exposed to many influences in the exploitation phase. Nowadays, the identified or measured properties can be used at home for numerous analyses and improvements, and on the basis of the latter, we can also prevent possible negative consequences in a timely manner. The rapid technological development of the construction of increasingly demanding facilities from the point of view of statics has also led to the development of measurement technology, with which we obtain data on the behaviour of the structure in a fast and very accurate way.

\section{CONCLUSION}

In the research we conducted, we wanted to get acquainted in more detail with modern geodetic and physical methods and evaluate them. The main goal of the construction monitoring was the analysis of the measured structure response signals using spectral analysis procedures and their mutual synchronization. In order to determine the consistency of the obtained results, we performed monitoring with three different geodetic devices and a physical device with the Instantel Minimate Plus seismograph. According to theoretical principles, we anticipated that synchronization between the used methods would be difficult before the monitoring was performed. Thus, the analysis was performed for each type of measurement partially. Because we wanted to include the influence of the sampling frequency of the measuring device on the results obtained throughout the test period and the further implementation of the actual control ring, we performed the tests with $6 \mathrm{~Hz}$ and $26 \mathrm{~Hz}$ data acquisition. Based on the performed experiment, we found that the difference in the obtained results is negligibly small and in some cases even exceeds the declared accuracy of the used measuring instruments. From the point of view of the presented and analysed responses of the structure to certain loads and the performed spectral analysis of individual signals, we can give the final results a final useful value. If we start from the value of vertical absolute displacements of geodetic measurements, it follows that in the case of measuring the response of the structure with geodetic measuring devices, the mutual difference is relatively negligible only in the case of robotic total stations used. The latter further defines the easy possibility of mutual coordination in practically all analysed events. As already mentioned, a more visible difference could be observed in the comparison of GNSS measurements with respect to the results obtained with RTS. Here, the deviations were still large even after the assumed subtracted eigenvalues, from which we also concluded that the use of GNSS and directly connected GPS systems makes much more sense in monitoring larger displacements or amplitudes over time.

The use of spectral analysis procedures and methods, such as the fast Fourier transform and the Lomb-Scargle algorithm, has proven to be an appropriate mathematical tool for the analysis and processing of measured signals. Using the Lomb-Scargle algorithm, we were able to additionally check the consistency of the source signals in the case of geodetic methods, using a spectral approximation in the range $0-1 \mathrm{~Hz}$. It turned out that the deviations in geodetic 
measurements are again larger compared to RTS and GNSS measurements. Even in the case of the use of physical methods, we were able to conclude that, based on spectral analysis, we obtained extremely important data from the measured signals, such as the dominant frequency and the corresponding amplitude. Spectral analysis has thus proven to be a good mathematical tool for advanced data processing in their comparison with each other.

We can therefore conclude that it makes sense to monitor the structure using both geodetic and physical methods, as only in this way can we gain a complete insight into the behaviour and response of the structure in its service life.

\section{REFERENCES}

[1] Lienhart, W.; Ehrhart, M.; Grick, M. (2017). High frequent total station measurements for the monitoring of bridge vibrations, Journal of Applied Geodesy, Vol. 11, No. 1, 1-8, doi:10.1515/jag2016-0028

[2] Lienhard, W.; Ehrhart, M. (2015). State of the art of geodetic bridge monitoring, Proceedings of the $10^{\text {th }}$ International Workshop of Structural Health Monitoring (IWSHM), 449-456, doi:10.12783/SHM2015/58

[3] Paar, R.; Marendić, A.; Jakopec, I.; Grgac, I. (2021). Vibration monitoring of civil engineering structures using contactless vision-based low-cost IATS prototype, Sensors, Vol. 21, No. 23, Paper 7952, 22 pages, doi: $10.3390 / \mathrm{s} 21237952$

[4] Koo, K. Y.; Brownjohn, J. M. W.; List, D. I.; Cole, R. (2013). Structural health monitoring of the Tamar suspension bridge, Structural Control and Health Monitoring, Vol. 20, No. 4, 609-625, doi:10.1002/stc. 1481

[5] Psimoulis, P. A.; Stiros, S. C. (2013). Measuring deflections of a short-span railway bridge using robotic total station, Journal of Bridge Engineering, Vol. 18, No. 2, 182-185, doi:10.1061/ (ASCE)BE.1943-5592.0000334

[6] Marendić, A.; Paar, R.; Grgac, I.; Damjanović, D. (2016). Monitoring of oscillations and frequency analysis of the railway bridge "Sava" using robotic total station, Proceedings of the $3^{\text {rd }}$ Joint International Symposium on Deformation Monitoring (JISDM), 8 pages

[7] Marendić, A.; Paar, R.; Duvnjak, I.; Buterin, A. (2014). Determination of dynamic displacements of the roof of sports hall Arena Zagreb, Proceedings of the INGEO $2014-6^{\text {th }}$ International Conference on Engineering Surveying, 13-20

[8] Psimoulius, P. A.; Stiros, S. C. (2007). Measurement of deflections and of oscillation frequencies of engineering structures using Robotic Theodolites (RTS), Engineering Structures, Vol. 29, No. 12, 3312-3324, doi:10.1016/j.engstruct.2007.09.006

[9] Kopačik, A.; Kyrinovič, P.; Kadlečikova, V. (2005). Laboratory tests of robot stations, Proceedings of the FIG Working Week 2005 and GSDI-8, 11 pages

[10] Radovanović, R. S.; Teskey, W. F. (2001). Dynamic monitoring of deforming structures: GPS versus Robotic Tacheometry Systems, Proceedings of the $10^{\text {th }}$ FIG International Symposium on Deformation Measurements, 61-70

[11] Lekidis, V.; Tsakiri, M.; Makra, K.; Karakostas, C.; Klimis, N.; Sous; I. (2005). Evaluation of dynamic response and local soil effects of the Evripos cable-stayed bridge using multi-sensor monitoring systems, Engineering Geology, Vol. 79, No. 1-2, 43-59, doi:10.1016/ j.enggeo.2004.10.015

[12] Čeryova, I.; Kubanka, P.; Kopačik, A.; Kyrinovič, P. (2002). Dynamic tests of robot stations, Proceedings of the FIG $22^{\text {nd }}$ International Congress of Deformations Measurement, 8 pages

[13] Chua, S. C. (2004). Testing of Robotic Total Stations for Dynamic Tracking, Ph.D. Thesis, University of Southern Queensland, Faculty of Engineering and Surveying, Darling Heights

[14] Gikas, V.; Daskalakis, S. (2006). Full scale validation of tracking total stations using a long stroke electrodynamic shaker, Proceedings of the $23^{\text {rd }}$ International FIG Congress: Shaping the Change, 11 pages

[15] Cosser, E.; Roberts, G. W.; Meng, X.; Dodson, A. H. (2003). Measuring the dynamic deformation of bridges using a total station, Proceedings of the $11^{\text {th }}$ FIG Symposium on Deformation Measurements, 605-612 
[16] Marendić, A.; Paar, R.; Damjanović, D. (2017). Measurement of bridge dynamic displacements and natural frequencies by RTS, Građevinar - Journal of the Croatian Association of Civil Engineers, Vol. 69, No. 4, 281-294, doi:10.14256/JCE.1804.2016

[17] Paar, R.; Roić, M.; Marendić, A.; Miletić, S. (2021). Technological development and application of photo and video theodolites, Applied Sciences, Vol. 11, No. 9, Paper 3893, 29 pages, doi:10.3390/app11093893

[18] Yi, Z.; Kuang, C.; Wang, Y.; Yu, W.; Cai, C.; Dai, W. (2018). Combination of high and low-rate GPS receivers for monitoring wind-induced response of tall buildings, Sensors, Vol. 18, No. 12, Paper 4100, 15 pages, doi:10.3390/s18124100

[19] Yang, X.; Stewart, K.; Tang, L.; Xie, Z.; Li, Q. (2018). A review of GPS trajectories classification based on transportation mode, Sensors, Vol. 18, No. 11, Paper 3741, 20 pages, doi:10.3390/ s18113741

[20] Novaković, G.; Marendić, A.; Grgac, I.; Paar, R.; Ilijaš, R. (2015). Locata - a new technology for high precision outdoor and indoor positioning, Geodetski list, Vol. 69 (92), No. 4, 279-304

[21] Poyraz, F. (2016). Uncertainty in the determination of fault locking depth and strike slip rates by GNSS measurements, Technical Gazette, Vol. 23, No. 1, 107-114, doi:10.17559/tv20141004090141

[22] Grgić, I.; Repanić, M.; Malović, I. (2017). Preliminary results of combined geodetic methods in monitoring, Technical Gazette, Vol. 24, No. 1, 301-308, doi:10.17559/TV-20150205124905

[23] Guntel, A.; Karabork, H.; Karasaka, L. (2018). Accuracy analysis of control point distribution for different terrain types on photogrammetric block, Technical Gazette, Vol. 25, Suppl. 1, 66-74, doi: $10.17559 /$ TV-20160801140840

[24] Ilçi, V.; Ozulu, I. M.; Arslan, E.; Alkan, R. M. (2018). Investigation on the accuracy of existing qibla directions of the mosques from different periods: a case study in Çorum City, Turkey, Technical Gazette, Vol. 25, No. 6, 1642-1649, doi:10.17559/tv-20170226111205

[25] Motoh, T. (2017). The Possibility of Measuring Dynamic Response of Structures Using NonContact Geodetic Methods, Master Thesis, University of Maribor, Maribor (in Slovene)

[26] Erdelyi, J.; Kopačik, A.; Kyrinovič, P. (2020). Spatial data analysis for deformation monitoring of bridge structures, Applied Sciences, Vol. 10, No. 23, Paper 8731, 14 pages, doi:10.3390/ app10238731

[27] Markelj, V.; Mlakar, R. (2008). Pedestrian bridge over the river Drava in Maribor, Gradbeni vestnik, Vol. 57, No. 4, 89-97

[28] Lomb, N. R. (1976). Least-squares frequency analysis of unequally spaced data, Astrophysics and Space Science, Vol. 39, No. 2, 447-462, doi:10.1007/BF00648343 